\title{
Problems of protection of urban ambient air pollution from industrial dust emissions
}

\author{
Valeriy Azarov ${ }^{1, *}$, Natalia Sergina ${ }^{1}$ and Tatyana Kondratenko ${ }^{2}$ \\ ${ }^{1}$ Volgograd State Technical University, Volgograd, st.Akademicheskaja, 1, Russia, 400074 \\ ${ }^{2}$ Don State Technical University, pl. Gagarina, 1, Rostov-on-Don, 344010, Russia
}

\begin{abstract}
The development of large cities accompanied by the development of the industry hashistorically led to the fact that now residential areas are located side by side with the industrial production. For instance, exactly this situation has developed in the city of Volgograd, as well as in other Russian cities, where sometimes the distance from large enterprises to a living area is $100 \mathrm{~m}$ or less. In addition, small-scale entrepreneurs usually place their production directly in their past places of residence. As a result, the content of harmful substances in the air of city blocks is much higher than the standards of hygiene require. It is obvious that the current situation can be improved through the use of modern, more advanced technologies. However, increasing the efficiency of air systems to protect the city from pollution and industrial emissions is an urgent task. The authors propose a version of the system layout, designed to reduce dust emissions in urban air.
\end{abstract}

\section{Introduction}

In recent decades, special attention is paid to the content in the ambient air of settlements particulate matter PM10 and PM2.5 [1-9], which are responsible for the development of cardiovascular and pulmonary diseases, including with the onset of death $[3,5,6]$, sources of income such particles into the air are divided into the following groups - industry, transport, fuel combustion, natural sources (naturally occurring dust and sea salt), unidentified sources of human origin [1].

According to experts, obtained on the basis of the results of statistical tools, the contribution of industry to PM10 particle content in the air of cities in the global average is $18 \%$, but may vary by region and level of development of the country [1]. For example, the share of the industrial activities have to: Turkey - 29\%, and in North and South America $26 \%$ in Western Europe - 22\%, in China - 21\% [1]. On average for countries with high income, this contribution is $21 \%$, in middle and low - $16 \%$ [1].

A similar pattern is observed for the industry's contribution to PM2.5 particles content that the average worldwide is $15 \%$. Industrial activity has the largest deposits in Japan (34\%), the Middle East and South Asia (27\%), Turkey (30\%), Brazil (19\%), South-East Asia (18\%), in Central Europe (17\%) [1]. However, according to the contribution of

\footnotetext{
*Corresponding author: tatkondr@,rambler.ru
} 
industry experts, in this case in middle- and low-income higher (16\%) than in high-income countries $(12 \%)$.

\section{Experimental section}

An example of the effect of various branches of the industry in the quality of urban air pollution on the content of fine dust is the data obtained by the authors as a result of many years of research and evaluation of fractional composition of various kinds of industrial dust, some of which are presented in Figure 1 [10].
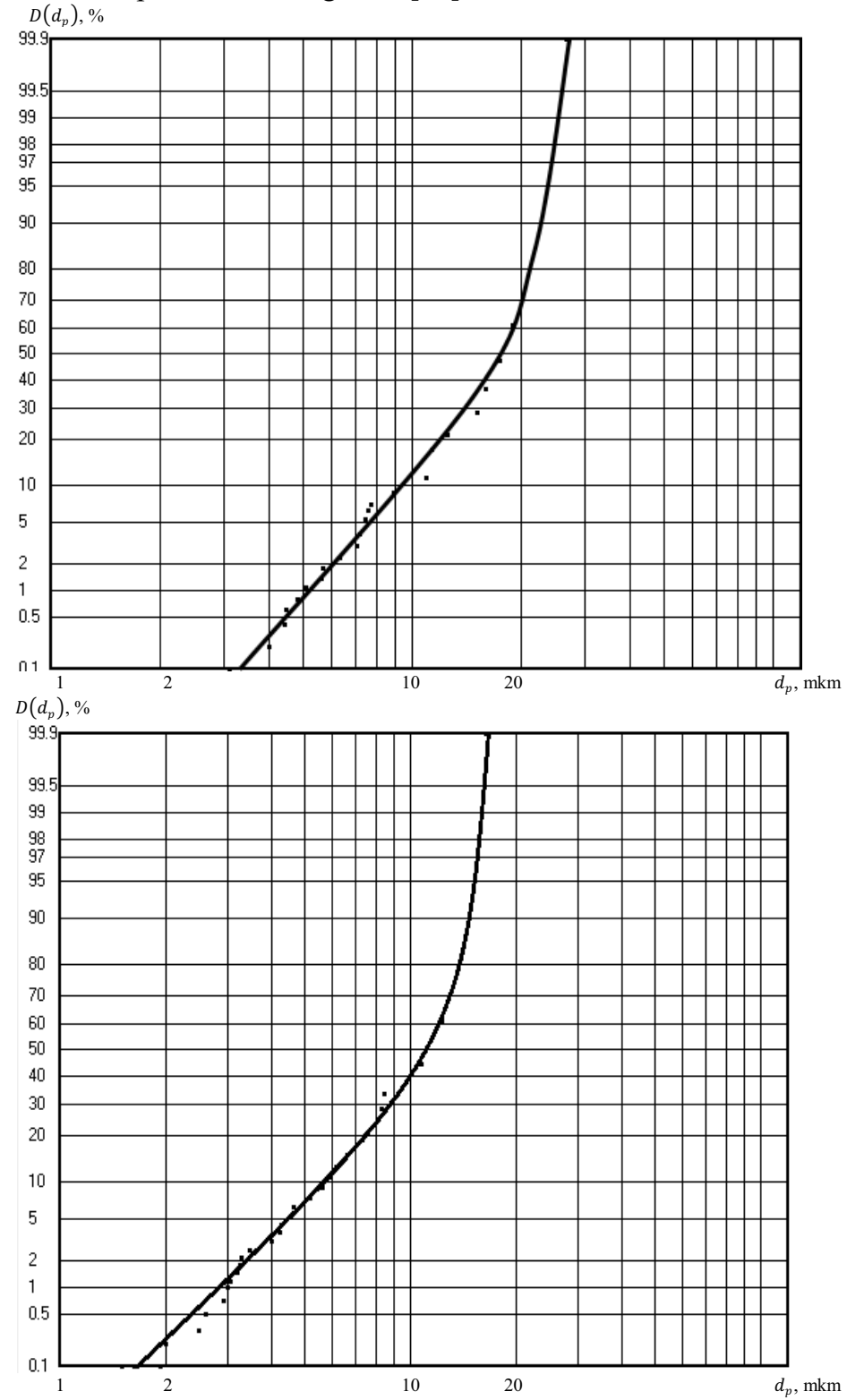

Fig. 1.The fractional composition of the dust in the air of a city block near the steel plant. a - the background values; $b$ - the period of melting steel [10] 
The data shown in pic. 1 show that as a result of dust emission during steel melting in an arc furnace PM10 particle content in the air city increases more than 3 -fold (from $12 \%$ to $40 \%$ ), PM2.5 particles content ranges from 0 to $0.8 \%$. In the production of asphalt concrete in the air on the border of residential development on the PM10 particles, accounting for $10 \%$, while the share of PM2.5 particles - $0.3 \%$ of the mass [11]. The concentration of particles with a size less than 10 microns is $300-330 \mathrm{mcg} / 3 \mathrm{~m}$ that exceeds the maximum allowable in the Russian concentration that on such an air particles localities established $300 \mathrm{mg} / \mathrm{m}^{3}$.

\section{Discussion section}

When selecting devices and systems for the protection of atmospheric air from the dust pollution guided by such basic indicators, such as high efficiency and low operating costs. Of all the existing diversity precipitators modifications in this respect are different devices with counter swirling flow (CSF), the benefits of which are found in the works of many researchers [12-17], and emission dedusting system CSF effectively exploited in various enterprises [15-21].

Fig. 2 shows one embodiment of a system of purification of industrial emissions of dust, composed of a series arrangement of two devices CSF suction hopper of the dust collector and returning the second stage recycle stream to the lower input apparatus CSF first stage [16].

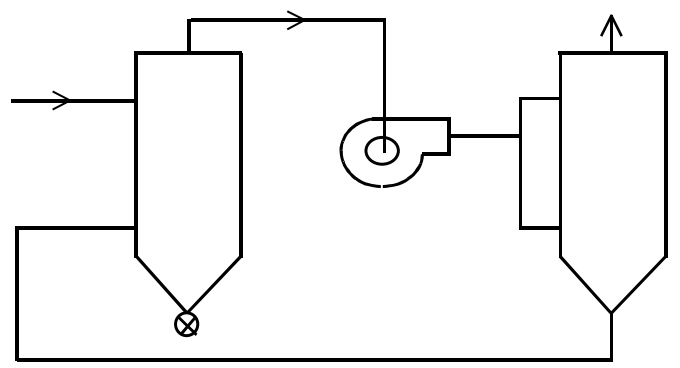

Fig. 2. Scheme of industrial emission treatment systems with devices from dust CDW

In this case, the efficiency of the dust collector due to the organization of the second stage increases by suction [12]:

$$
\Delta \eta_{2}=0,148 K(0,5-K)
$$

where $\mathrm{K}$ - volume fraction flowing in a dusty mixture sucked out of the hopper apparatus a second stage CSF (ranges from 0.15 to 0.35 [12]).

This drag coefficient of the second dust collector, which characterizes the electricity costs for the implementation of the process emissions dedusting is reduced to 1.5-1.6 times [12].

To assess the overall effectiveness of dust collection set up a system of balance equations of dust streams [21] 


$$
\left\{\begin{array}{c}
G_{\text {cau } 1}+c_{\text {out } 1} L_{a s}=c_{a s} L_{a s}+c_{\text {suc }} L_{\text {suc }} \\
G_{\text {cau } 1}=\eta_{1}\left(c_{a s} L_{a s}+c_{\text {suc }} L_{\text {suc }}\right) \\
G_{\text {cau } 2}=\eta_{2}\left(c_{\text {out } 1} L_{a s}+c_{\text {out } 1} L_{\text {suc }}\right) \\
G_{\text {cau } 2}+c_{\text {out } 2} L_{\text {as }}=c_{\text {out } 1} L_{a s}+c_{\text {out } 1} L_{\text {suc }} \\
G_{\text {cau } 2}=c_{\text {suc }} L_{\text {suc }}
\end{array}\right.
$$

By definition, the overall efficiency of the system $\eta_{\text {sys }}$ will be:

$$
\eta_{\text {sys }}=\frac{c_{\text {as }} L_{\text {as }}-c_{\text {out } 2} L_{\text {out } 2}}{c_{\text {as }} L_{\text {as }}}=1-\frac{c_{\text {out } 2} L_{\text {out } 2}}{c_{\text {as }} L_{\text {as }}}
$$

To solve the system (2) with respect to $\mathrm{c}_{\text {out } 2} \mathrm{~L}_{\text {out } 2}=\mathrm{c}_{\mathrm{as}} \mathrm{L}_{\mathrm{as}}$ divide both sides of each equation on $\mathrm{C}_{\mathrm{as}} \mathrm{L}_{\mathrm{as}}$ and obtain a system of equations of the form:

$$
\left\{\begin{array}{c}
\bar{G}_{\text {cau } 1}+\bar{c}_{\text {out } 1} \bar{L}_{\text {as }}=1+\bar{c}_{\text {suc }} \bar{L}_{\text {suc }} ; \\
\bar{G}_{\text {cau } 1}=\eta_{1}\left(1+\bar{c}_{\text {suc }} \bar{L}_{\text {suc }}\right) \\
\bar{G}_{\text {cau } 2}=\eta_{2}\left(\bar{c}_{\text {out } 1} \bar{L}_{\text {as }}+\bar{c}_{\text {out } 1} \bar{L}_{\text {suc }}\right) ; \\
\bar{G}_{\text {cau } 2}+\bar{c}_{\text {out } 2} \bar{L}_{\text {as }}=\bar{c}_{\text {out } 1} \bar{L}_{\text {as }}+\bar{c}_{\text {out } 1} \bar{L}_{\text {suc }} \\
\bar{G}_{\text {cau } 2}=\bar{c}_{\text {suc }} \bar{L}_{\text {suc }} .
\end{array}\right.
$$

Putting term wise first two equations (2)

$$
\begin{gathered}
c_{\text {out } 1} L_{\mathrm{as}}+c_{\mathrm{as}} L_{\mathrm{as}}+c_{\mathrm{suc}} L_{\mathrm{suc}}=\eta_{1}\left(c_{\mathrm{as}} L_{\mathrm{as}}+c_{\mathrm{suc}} L_{\text {suc }}\right) ; \\
\left(1-\eta_{1}\right)\left(c_{\mathrm{as}} L_{\mathrm{as}}+c_{\text {suc }} L_{\mathrm{suc}}\right)=c_{\text {out } 1}\left(L_{\mathrm{as}}+L_{\text {suc }}\right)
\end{gathered}
$$

Dividing by $\mathrm{c}_{\mathrm{as}} \mathrm{L}_{\mathrm{as}}$, we obtain:

$$
\left(1-\eta_{1}\right)\left(1+\bar{c}_{\text {suc }} \bar{L}_{\text {suc }}\right)=\bar{c}_{\text {out } 1}\left(1+\bar{L}_{\text {suc }}\right)
$$

Solving the system (4) with respect to $\overline{\overline{\mathrm{c}}}_{\text {out } 2} \overline{\mathrm{L}}_{\mathrm{as}}$ by process of elimination, we get

$$
\begin{gathered}
\eta_{2} \bar{c}_{\text {out } 1}\left(\bar{L}_{\text {as }}+\bar{L}_{\text {suc }}\right)=\bar{c}_{\text {out } 1}\left(\bar{L}_{\text {as }}+\bar{L}_{\text {suc }}\right)-\bar{c}_{\text {out } 2} \bar{L}_{\text {out } 2} ; \\
\left(1-\eta_{2}\right) \bar{c}_{\text {out } 1}\left(\bar{L}_{\text {as }}+\bar{L}_{\text {suc }}\right)=\bar{c}_{\text {out } 2} \bar{L}_{\text {out } 2} ; \\
\bar{c}_{\text {suc }} \bar{L}_{\text {suc }}=\eta_{2} \bar{c}_{\text {out } 1}\left(1+\bar{L}_{\text {suc }}\right)
\end{gathered}
$$

or

$$
\left\{\begin{array}{c}
\left(1-\eta_{1}\right)\left(1+\bar{c}_{\text {suc }} \bar{L}_{\text {suc }}\right)=\bar{c}_{\text {out } 1}\left(1+\bar{L}_{\text {suc }}\right) \\
\left(1-\eta_{2}\right) \bar{c}_{\text {out } 1}\left(\bar{L}_{\text {as }}+\bar{L}_{\text {suc }}\right)=\bar{c}_{\text {out } 2} \bar{L}_{\text {out } 2} ; \\
\bar{c}_{\text {suc }} \bar{L}_{\text {suc }}=\eta_{2} \bar{c}_{\text {out } 1}\left(1+\bar{L}_{\text {suc }}\right) ; \\
\eta_{1}=\eta_{1}\left(c_{\text {suc }} / c_{\text {as }}, L_{\text {suc }} / L_{\text {as }}\right) ; \\
\eta_{2}=\eta_{2}\left(\bar{c}_{\text {out } 1}, \bar{L}_{\text {suc }}\right)
\end{array}\right.
$$

Taking values $\eta_{2}$ constant and solving the system (5) with respect to the parameter $1 /$ $\left(\left(1-\eta_{1}\right)\right)$, we obtain:

$$
\frac{1}{1-\eta_{1}}=\eta_{2}\left(1+\frac{1}{\bar{c}_{s u c} \bar{L}_{s u c}}\right)
$$

It is known that the effectiveness of the vortex apparatus substantially depends on the ratio of the volume flow and dusty supplied through upper and lower inlets [12]. Taking as 
a first approximation, that $\eta_{1}=\eta_{1}\left(\overline{\mathrm{c}}_{\text {suc }}, \overline{\mathrm{L}}_{\text {suc }}\right)$, express this function in terms of a number of the following form:

$$
\frac{1}{1-\eta_{1}}=1-\frac{A_{1}}{\bar{c}_{\text {suc }} \bar{L}_{s u c}}+\frac{A_{2}}{\left(\bar{c}_{\text {suc }} \bar{L}_{\text {suc }}\right)^{2}}-\frac{A_{3}}{\left(\bar{c}_{\text {suc }} \bar{L}_{s u c}\right)^{3}}+\frac{A_{4}}{\left(\bar{c}_{\text {suc }} \bar{L}_{s u c}\right)^{4}}+\ldots
$$

As a second approach, we assume significant first three terms of the series. Then:

$$
\eta_{2}\left(1+\frac{1}{\bar{c}_{\text {suc }} \bar{L}_{\text {suc }}}\right)=1-\frac{A_{1}}{\bar{c}_{\text {suc }} \bar{L}_{\text {suc }}}+\frac{A_{2}}{\left(\bar{c}_{\text {suc }} \bar{L}_{\text {suc }}\right)^{2}}
$$

We get the quadratic equation:

$$
\bar{c}_{\text {suc }}^{2}\left(1-\eta_{1}\right)-\bar{c}_{\text {suc }}\left(\frac{A_{1}+\eta_{2}}{\bar{L}_{\text {suc }}}\right)+\frac{A_{2}}{\bar{L}_{\text {suc }}^{2}}=0,
$$

whose solution has the form:

$$
\bar{c}_{\text {suc }}=\frac{A_{1}+\eta_{2}+\sqrt{2 \eta_{2}\left(A_{1}+2 A_{2}\right)+\left(A_{1}^{2}-4 A_{2}\right)+\eta_{2}^{2}}}{2\left(1-\eta_{2}\right) \bar{L}_{s u c}}
$$

Substituting (8) into (6) we obtain:

$$
\frac{1}{1-\eta_{1}}=\eta_{2}\left(1+\frac{2\left(1-\eta_{2}\right)}{A_{1}+\eta_{2}+\sqrt{2 \eta_{2}\left(A_{1}+2 A_{2}\right)+\left(A_{1}^{2}-4 A_{2}\right)+\eta_{2}^{2}}}\right)
$$

Then, the total efficiency of the system will be

$$
\eta_{s y s}=1-\frac{A_{1}+\eta_{2}+\sqrt{2 \eta_{2}\left(A_{1}+2 A_{2}\right)+\left(A_{1}^{2}-4 A_{2}\right)+\eta_{2}^{2}}}{2 \eta_{2}}
$$

In the expressions (2) - (10), the following notation: $\boldsymbol{c}_{\mathbf{a s}}, \boldsymbol{c}_{\mathbf{s u c}}$ - dustiness of air supplied to the upper and lower inlets of the first stage scrubber systems and aspiration from the hopper of the dust collector of the second stage, respectively, $\mathrm{mkg} / \mathrm{m} 3 ; \boldsymbol{L}_{\mathbf{a s}}, \boldsymbol{L}_{\text {suc }^{-}}$air flow supplied to the upper and lower bushings of the apparatus of the first stage and the aspiration system of the second stage of the dust collector hopper respectively $\mathrm{m} 3 / \mathrm{h} ; \boldsymbol{c}_{\text {out1 }}$, $\boldsymbol{c}_{\text {out2 }}$ - dustiness of air at the outlet of the first stage and the dust collector at the outlet of the second stage of the dust collector into the atmosphere, respectively $\mathrm{mkg} / \mathrm{m} 3 ; \boldsymbol{G}_{\text {cau1 }}, \boldsymbol{G}_{\text {cau2 }}{ }^{-}$ the mass of dust captured in CSF devices, $\mathrm{kg} / \mathrm{h} ; \boldsymbol{\eta}_{\mathbf{1}}, \boldsymbol{\eta}_{\mathbf{2}}, \boldsymbol{\eta}_{\boldsymbol{s} y \boldsymbol{s}}$ - CSF efficiency devices and systems.

Values of the $\mathbf{A}_{\mathbf{1}}$ and $\mathbf{A}_{\mathbf{2}}$ coefficients are determined based on the results of experimental studies depending on the mode of operation of dust collectors. The solution finds by the method of successive approximations, not later than the third cycle of calculations.

\section{Conclusions}

The results of pilot tests confirmed the feasibility of the proposed system with the use of devices emissions CDW treatment plants and recycling of collected products for the protection of urban air pollution from fine dust receipts. Thus, in the production of asphalt concrete, in comparison with conventional dust control systems are arranged in two series arranged cyclones, dust emissions were reduced by 3.9 times. At the same PM10 particle 
content in the stream, emitted into the atmosphere after treatment decreased by $36 \%$, PM 2.5 particle content $-25 \%$.

\section{References}

1. F. Karagulian, K. Belis, K. F. C. Dora, A. Prüss-Ustün, S. Bonjour, Ch.A. Rochani, M. Amann, Atmos. Environ,120, 475 (2015)

2. Federal Register, EPA,71, 61144 (2006)

3. P.J. Lioy, P.G. Georgopoulos, Environ. Health Perspect, 119, 1351 (2011)

4. N. Chu, J.B. Kadane, C.I. Davidson, Environ. Sci. Technol,43, 2407 (2009)

5. Barraza-Villarreal, J. Sunyer, L. Hernandez-Cadena, M.C. Escamilla-Nunez, J. J. Sienra-Monge, M. Ramirez-Aguilar, M. Cortez-Lugo, D. Diaz-Sanchez, A.C. Olin, I. Romieu, Environ. Health. Perspect, 116, 832 (2008)

6. T.H. Self, C.R. Chrisman, D.L. Mason, M. J. Rumbak, J. Asthma,42, 807 (2005)

7. F. Karagulian, Atmos. environ.,71, 26 (2013)

8. V. N. Azarov, I. V. Tertishnikov, N. A. Marinin, Bul. VolgGASU,25(44), 402 (2011)

9. V.A. Drozd, P.F. Kiku, V.Y. Ananiev, Proceedings of the Samara Scientific Center of the Russian Academy of Sciences, 5(2), 646 (2015)

10. E.A.Semyonova, N.M. Sergina, D.V. Azarov, I.A.Gvozdkov, Modern Science and Innovations, 4(12), 162 (2015)

11. M.A. Nikolenko, N.V. Neumerzhickaja, N.M. Sergina, M.V. Belonozhko, Eng. Bul. of Don, 3, 3191 (2015)

12. N.M. Sergina, Alternative Energy and Ecology, 11, 43 (2013)

13. V. N. Azarov, D.V. Lukanin, D.P. Borovkov, A.M. Redhwan, International Review of Mechanical Engineering, 5, 851 (2014)

14. V. N. Azarov, D.P. Borovkov, A.M. Redhwan, International Review of Mechanical Engineering, 4, 750 (2014)

15. N.M. Sergina, M.S.A. Abduljalil, L.M. Abramova, Eng. Bul. of Don, 3, 3218 (2015)

16. A.N. Bogomolov, N.M. Sergina, T.O. Kondratenko, Procedia Engineering, 150, 2036 (2016)

17. N.M. Sergina, M.S.A. Abduljalil, L.M. Abramova, M. Ostaali, Modern Science and Innovations, 1(13), 168 (2016)

18. V. N. Azarov, N.M. Sergina, Construction Materials, 8, 14 (2003)

19. N.M. Sergina, E.A. Semjonova, T.O. Kondratenko, Alternative Energy and Ecology, 112, 43 (2013)

20. N.M. Sergina, D.V. Azarov, E.V. Gladkov, Construction Materials, 2, 86 (2013)

21. N.M. Sergina, M.S.A. Abduljalil, Bul. VolgGASU,42(61), 108 (2015) 